\title{
Genetic Analysis Algorithm for the Study of Patients with Multiple Congenital Anomalies and Isolated Congenital Heart Disease $^{\dagger}$
}

\author{
Marisol Delea ${ }^{1}$, Lucía S. Massara ${ }^{2}$, Lucía D. Espeche ${ }^{1}$, María P. Bidondo ${ }^{1,3}$, Pablo Barbero ${ }^{1}$, Jaen Oliveri ${ }^{2}$, \\ Paloma L. Brun 2,4, Mónica Fabro 5, Micaela Galain 5, Cecilia S. Fernández 5, Melisa Taboas 1, Carlos D. Bruque 1,

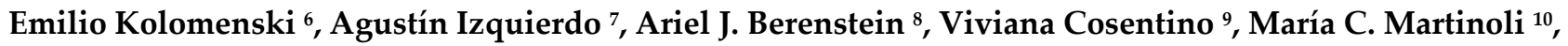 \\ Mariana Vilas ${ }^{11}$, Mónica Rittler 11, Rodrigo Mendez ${ }^{1}$, Lilian Furforo ${ }^{11}$, Rosa Liascovich ${ }^{1}$, Boris Groisman ${ }^{1}$, \\ Sandra Rozental ${ }^{1}$, Liliana B. Dain ${ }^{1,6, *}$ and the PID ACM-CC Group
}

Citation: Delea, M.; Massara, L.S.; Espeche, L.D.; Bidondo, M.P.; Barbero, P.; Oliveri, J.; Brun, P.L.; Fabro, M.; Galain, M.; Fernández, C.S.; et al. Genetic Analysis Algorithm for the Study of Patients with Multiple Congenital Anomalies and Isolated Congenital Heart Disease. Proceedings 2021, 76, 8 . https://doi.org/10.3390/IECGE-07151

Published: 2 November 2020

Publisher's Note: MDPI stays neutral with regard to jurisdictional claims in published maps and institutional affiliations.

Copyright: () 2020 by the authors. Licensee MDPI, Basel, Switzerland. This article is an open access article distributed under the terms and conditions of the Creative Commons Attribution (CC BY) license (http://creativecommons.org/licenses/by/4.0/).
1 Centro Nacional de Genética Médica "Eduardo Castilla"- Administración Nacional de Laboratorios e Institutos de Salud“Carlos G. Malbrán”, Av. Las Heras 2670, 1425 Buenos Aires, Argentina; marisoldelea@gmail.com (M.D.); lespeche@yahoo.com.ar (L.D.E.); mariapazbidondo@gmail.com (M.P.B.); pablobarbero63@hotmail.com (P. B.); mtaboas@anlis.gov.ar (M.T.); bruquecarlos@gmail.com (C.D.B.); rodrigomendezh@gmail.com (R.M.); rosaliascovich@hotmail.com (R.L.); bgroisman@gmail.com (B.G.); sandrarozental@yahoo.com.ar (S.R.)

2 Hospital de Alta Complejidad en Red El Cruce-SAMIC, Av. Calchaquí 5401, 1888 Florencio Varela, Buenos Aires, Argentina; luciasolemassara@gmail.com (L.S.M.); jaenoliveri@hotmail.com (J.O.); brunpaloma@gmail.com (P.L.B.)

$31^{\circ}$ Unidad académica de Histología, Embriología, Biología Celular y Genética, Facultad de Medicina UBA, Paraguay 2155, 1121 Buenos Aires, Argentina

4 Ministerio de Salud, Av. 9 de Julio 1925, 1091 Buenos Aires, Argentina

5 Novagen, Viamonte 1430, 1055 Buenos Aires, Argentina; mfabbro@novagen.com.ar (M.F.); mgalain@fertimed.com.ar (M.G.); cecilia.fernandez@novagen.com.ar (C.S.F.)

6 Departamento de Fisiología, Biología Molecular y Celular, Instituto de Biociencias, Biotecnología y Biología Traslacional (iB3), Facultad de Ciencias Exactas y Naturales- UBA, Intendente Güiraldes 2160 pabellón 2, 1428 Buenos Aires, Argentina; ekolomenski@gmail.com (E.K.); ldain@fbmc.fcen.uba.ar (L.B.D.)

7 Centro de Investigaciones Endocrinológicas “Cesar Bregada”, Gallo 1330, 1425 Buenos Aires, Argentina; aguizquierdo@gmail.com

8 Instituto Multidisciplinario de Investigaciones en Patologías Pediátricas, Gallo 1330, 1425 Buenos Aires, Argentina; arieljberenstein@gmail.com

9 Hospital Interzonal General de Agudos Luisa Cravenna de Gandulfo, Balcarce 351, 1832 Lomas de Zamora, Buenos Aires, Argentina; viviconsentino@hotmail.com

10 Hospital Sor Maria Ludovica, Calle 14 1631, 1904 La Plata, Buenos Aires, Argentina; celestemartinoli@yahoo.com.ar

11 Hospital Materno Infantil Ramón Sardá, Esteban de Luca 2151, 1246 Buenos Aires, Argentina; marianavilas@hotmail.com (M.V.); lilianfurforo@gmail.com (L.F.); rittlerm@gmail.com (M.R.)

* Correspondence: ldain@fbmc.fcen.uba.ar; Tel.: +54-11-48012326 (ext. 408)

+ Presented at the First International Electronic Conference on Genes: Theoretical and Applied Genomics, 2-30 November 2020, Available online: https://iecge.sciforum.net/.

Abstract: In this work, we aim to identify the genetic causes of pathogenesis in Argentinean patients with multiple congenital anomalies (MCA) and isolated Congenital Heart Disease (iCHD). We recruited $174 \mathrm{MCA}$ and 194 iCHD patients from 15 public hospitals. Karyotyping was performed for MCA patients, and MLPA for conotruncal CHD or suspected 2q11 Deletion Syndrome (22q11DS). Selected samples were analyzed by array-CGH (Comparative genomic hybridization) $(n=89)$ and/or Next-Generation Sequencing (NGS) $(n=18)$. We successfully analyzed 252/368 patients: 14 had cytogenetic abnormalities, 27 had imbalances in 22q11, and 16 had other clinically relevant copy number variations (CNVs). NGS revealed 12 relevant nucleotide variants (five novels). Combining molecular, clinical and genetic evaluations, the diagnostic yield was $26.2 \%$. 
Keywords: congenital anomalies; multiple congenital anomalies; congenital heart disease; chromosomal abnormalities; array-CGH; next generation sequencing

\section{Introduction}

Congenital anomalies (CAs) are morphological and/or functional disorders of prenatal origin resulting from morphological disturbances in the process of human development $[1,2]$. CAs affect $3-5 \%$ of newborns and are mostly presented in isolation, but nearly 20 to $30 \%$ of infants with birth defects have multiple congenital anomalies (MCAs) involving major anomalies in different organs and systems [2,3]. In Argentina, CA represents the second leading cause of infant mortality after perinatal conditions. Newborns presenting MCA have a prevalence of 2.26/1000 births, whereas Congenital Heart Disease (CHD) is the most frequent CA, with a prevalence at birth of $4.06 / 1000$ newborns [4].

The etiology of these defects is widely recognized as heterogeneous with contributions of genetic $(\sim 40 \%)$ and environmental/maternal factors $(\sim 5-10 \%)[5,6]$. Numerical and structural chromosomal abnormalities account for approximately $15 \%$ of patients with major CA [7]. Microdeletion and microduplication, also known as copy number variations (CNVs), have been described in 10-17\% MCA patients [8,9]. Finally, single-gene defects account for a number of well-recognized MCA syndromes and are present in $3-5 \%$ of patients with CHD [10]. Nevertheless, in nearly $50 \%$ of the cases, the etiology remains unknown.

Although largely studied in several populations, there are few studies on the genetic contribution on CA in Latin America [11-14]. The aim of this study was to identify the genetic causes of pathogenesis in Argentinian patients with MCA and isolated CHD (iCHD).

\section{Materials and Methods}

\subsection{Ethical Approval}

All procedures performed in this study were in accordance with institutional and/or national research committee ethical standards and with the 1964 Helsinki declaration and its later amendments or comparable ethical standards. Written informed consent was obtained from parents of all patients involved in this study prior to history recording and sampling. The study was approved by the ethics committee of the Administración Nacional de Laboratorios e Institutos de Salud (ANLIS), Buenos Aires, Argentina (Acta \# 14, 16 September 2013).

\subsection{Patients}

We recruited 368 patients (174 MCA and 194 iCHD) born between June 2015 and August 2019 from 13 public hospitals from the city and province of Buenos Aires participating in the National Network of Congenital Anomalies of Argentina (RENAC) and patients up to 16 years attending at the Genetic Services of Hospital Sor María Ludovica and Hospital El Cruce, Province of Buenos Aires. All patients were evaluated by a neonatologist and a clinical geneticist. A complete physical examination was performed, and detailed individual and family history were retrieved. Case definitions are described elsewhere [2]. In the present study, we excluded cases with Down Syndrome phenotype or functional CA, newborns $<37$ weeks of gestation with ductus and those with Foramen oval independent of the gestational age. Among MCA, the female/male ratio was 1.03 (87/84, 3 had ambiguous genitalia) and 1.02 (98/96) for iCHD cases. Median and mean age of patients were 0.15 and 1.08 years, respectively. A total of 31 patients had clinical suspicion of a specific syndrome at the time of their inclusion. 


\subsection{Algorithm Used for Patients' Analyses}

DNA from peripheral blood was obtained from all patients, while karyotyping was performed for those presenting with MCA. Multiplex-dependent ligation probe amplification (MLPA) analysis was performed in 137 patients presented either with conotruncal CHD (CCHD, $n=105,26 \mathrm{MCA}, 79 \mathrm{iCHD)}$ [11] or clinical manifestations compatible with 22q11DS regardless of the presence of CCHD ( $n=32,16 \mathrm{MCA}, 16 \mathrm{iCHD})$. In addition, $89 \mathrm{MCA}$ samples with normal karyotype or unsolved cytogenetic studies were selected for chromosomal microarray analysis (CMA). Finally, 18 patients were selected for targeted or exome next generation sequencing (NGS).

\subsection{Cytogenetic Analysis}

Cytogenetic analysis was performed in peripheral blood lymphocytes by standard trypsin-Wright (GTW) banding technique according to standard procedures. The International System for Human Cytogenomic Nomenclature 2016 (ISCN) was used for nomenclature reference [15].

\subsection{Multiplex-Dependent Ligation Probe Amplification Analysis (MLPA)}

The MLPA analysis was performed using SALSA P250-B2 MLPA kit (MRC-Holland, Amsterdam, the Netherlands) as previously described [11].

\subsection{Chromosomal Microarray Analysis (CMA)}

Patients were studied with the ISCA v2 $8 \times 60 \mathrm{~K}$ (Agilent, Santa Clara, CA, USA) platform as previously described [16,17]. In some cases, familial samples were analyzed for a full interpretation of the proband's array results.

\subsection{Next Generation Sequencing (NGS) Analysis}

Approximately 1 ug of DNA from a group of 18 selected patients with suspected known syndromes and/or familiar history was analyzed by targeted NGS (TruSight ${ }^{\circledR}$ Cardio Sequencing kit, Illumina, San Diego, CA, USA $(n=6)$ ) or whole exome sequencing (WES, SureSelect Human All Exon V6 and V7 kit, Agilent, Santa Clara, CA, USA, $(n=12)$ ), followed by an in silico selection of candidate genes for variant analysis. Phenotypedriven gene lists of interest were developed internally. Variants were interpreted using American College of Medical Genetics and Genomics (ACMG) guidelines [18]. All identified sequence changes of interest were confirmed by Sanger sequencing.

\section{Results and Discussion}

We have conducted a detailed genetic analysis in Argentinian patients with MCA and iCHD. A total of 276 patients were studied by at least one technique, from which 252 were successfully analyzed (145 MCA and $107 \mathrm{iCHD})$. Although microarray testing has proven to be especially useful as the first-tier evaluation in the identification of pathogenic CNVs among patients with MCA [9], due to financial limitations in Argentina, this technique is not widely available in the public health system. Therefore, cytogenetic analysis is used as the first-tier genetic test for patients referred with MCA.

Of the $174 \mathrm{MCA}$ patients, we successfully karyotyped 104. In 14, an abnormal karyotype was observed, including six patients with trisomy 18, and one with a trisomy 13. The diagnostic yield of karyotyping was $13.4 \%$, similar to previous results showing chromosomal abnormalities in approximately $15 \%$ of patients with major CA [7]. However, it should be noted that approximately $40 \%$ of cases did not have a karyotype due to culture failure or difficulties in sample referral. Some cases, indeed, were diagnosed after CMA (see below). This observation reinforces the importance of applying array-CGH routinely to overcome technical difficulties in cytogenetic studies.

The 22q11 Deletion Syndrome (22q11DS) represents the most common microdeletion syndrome in humans. Conotruncal CHD (CCHD) is one of the most common phenotypic 
manifestations in 22q11DS. However, imbalances in the 22q11 region were also found in a significant number of patients with isolated CCHD $[19,20]$. We successfully resolved 132 of the 137 samples selected for MLPA analysis and found $27(20.5 \%)$ patients with an imbalance (Table 1). Similar to our previous results [11], we observed 22q11 imbalances in $23 \%$ of the patients with CCHD. Although most prevalent among patients with MCA, we found a 22q11 imbalance in $22 \%$ of the patients with isolated CCHD. In these cases, an early diagnosis and interventions are key to prevent clinical complications later in life.

Table 1. MLPA analysis in patients with CCHD or with suspected 22q11DS not presenting CCHD.

\begin{tabular}{ccccc}
\hline Imbalances & CCHD MCA & iCCHD & Suspected 22q11DS & Total \\
\hline None & 18 & 60 & 27 & 105 \\
\hline Del 22q11 $(3 \mathrm{Mb})$ & 5 & 13 & 3 & 21 \\
\hline Del 22q11 $(1.5 \mathrm{Mb})$ & 1 & 2 & - & 3 \\
\hline Dup 22q11 $(1.5 \mathrm{Mb})$ & 1 & 1 & - & 2 \\
\hline Del 22q11.2 $(T B X 1)$ & - & 1 & - & 1 \\
\hline Total & 25 & 77 & 30 & 132 \\
\hline
\end{tabular}

Del: deletion; Dup: duplication; CCHD: conotruncal CHD; MCA: multiple congenital anomalies; iCCHD. isolated CCHD; 22q11DS: 22q11 deletion syndrome (without CCHD). 1: These patients had an iCHD. Partial results of MLPA analysis have been published previously [11].

As mentioned above, microarray testing has been proven to be especially useful in the identification of pathogenic CNVs among patients with MCA [8,9]. We successfully analyzed 84/89 selected samples and found 17 clinically relevant (pathogenic or likely pathogenic) CNVs in 16 patients, representing a diagnostic yield of $19 \%$ (Table 2). In addition, we found seven CNVs classified as Variants of uncertain significance (VUS) in seven patients.

Table 2. Clinically relevant CNVs found by array-CGH in MCA patients.

\begin{tabular}{|c|c|c|c|c|}
\hline ACMG & Patients & Imbalances & Size (Mb) & OMIM \# \\
\hline \multirow{14}{*}{ Pathogenic } & \multirow{14}{*}{14} & $\begin{array}{c}\text { Del 1p36.33p36.23; Dup } \\
7 \mathrm{q} 35 \mathrm{q} 36.3^{1,2}\end{array}$ & $7.10 ; 12.2$ & 607,872 \\
\hline & & Del 2q24.2q31.1 & 13.73 & - \\
\hline & & Del 2q14.2q14.3 & 7 & - \\
\hline & & Del 5q22.23 & 0.02 & - \\
\hline & & Del 7q36.1q36.31 & 10.06 & - \\
\hline & & Dup 7q11.23 & 1.27 & 609,757 \\
\hline & & Del 8q21.11q21.32,4 & 11.19 & 614,230 \\
\hline & & Del 9q22.2q31.1 & 12 & - \\
\hline & & $\mathrm{T}^{2} 3^{1}$ & - & - \\
\hline & & Del 15q14 & 6.22 & 616,898 \\
\hline & & Del 16p12.2 & 0.57 & 136,570 \\
\hline & & T18 1 & - & - \\
\hline & & Dup Xp22.33 & 1.7 & - \\
\hline & & TX, T145 & - & - \\
\hline \multirow{2}{*}{$\begin{array}{c}\text { Likely } \\
\text { Pathogenic }\end{array}$} & \multirow{2}{*}{2} & Del 3p21.31 & 4.1 & - \\
\hline & & Del 17q25.3 & 0.50 & - \\
\hline
\end{tabular}

ACMG: American College of Medical Genetics and Genomics [21] classification; \#: number, Dup: duplication, Del: deletion, T: trisomy. 1: Cytogenetic study failed. 2: Parents presented a normal karyotype. 3: This patient was also studied by NGS, see below. 4: This patient presented a $46, X Y, t(1 ; 2)(\mathrm{q} 25 ; \mathrm{q} 21)$ karyotype. 5: Already described [17]. 
The diagnosis yield - as a second or third-tier test for a cohort of MCA patients - of $19 \%$ is in accordance with similar reports from other populations [2,22]. It should be noted, however, that the diagnostic yield of CMA depends on many factors, including the resolution of the platform used, patient selection criteria, sample size, previous testing performed and the referring indication for testing.

Introduction of CMA, as well as NGS techniques into a diagnostic workflow, requires proper clinical validation. This becomes a challenge in neonatal and infant populations. As for CMA, NGS techniques are not widely available in the public health system in Argentina, mainly due to their high cost. In that sense, we studied a group of patients using NGS analysis based on a precise characterization of the patient's phenotype, the socalled phenotype-first approach. In addition, we performed an exhaustive phenotypedriven gene list of interest developed internally to further allow the successful finding of clinically relevant genetic variants. By applying this approach, 12 out of 18 patients $(67 \%)$ had clinically relevant (pathogenic or likely pathogenic) nucleotide variants (Table 3 ). In addition, five other genetic variants classified as VUS were found (three in iCHD, two in MCA).

Table 3. Clinically relevant genetic variants found after NGS analysis.

\begin{tabular}{|c|c|c|c|}
\hline Gene & ACMG & Protein Change & Phenotype \\
\hline SHH & Likely Pathogenic & p.His270Tyr & MCA \\
\hline MYH11 & Pathogenic & p.? ${ }^{1,2}$ & MCA \\
\hline PTPN11 & Pathogenic & p.(Ala461Thr) & MCA $^{3}$ \\
\hline FOXL2 & Likely Pathogenic & p.(Tyr215Cys) & MCA \\
\hline PTPN11 & Pathogenic & p.Asn308Asp & MCA \\
\hline EP300 & Pathogenic & p.(Gln2361Ter) & MCA $^{1}$ \\
\hline PTPN11 & Pathogenic & p.(Asp61Asn) & MCA $^{3}$ \\
\hline KAT6B & Pathogenic & p.(Thr1525IlefsTer25) & MCA $^{5}$ \\
\hline MYBPC3 & Likely Pathogenic & p.(Arg726Cys) & MCA/iCHD $^{3}$ \\
\hline RAF1 & Pathogenic & p.(Ser257Leu) & iCHD $^{3}$ \\
\hline MYH7 & Likely Pathogenic & p.(Asn224Ile) $)^{1}$ & iCHD $^{3}$ \\
\hline
\end{tabular}

iCHD: isolated congenital heart disease; MCA: multiple congenital anomalies; ACMG: American College Medical Genetics and Genomics classification [18]. 1: Novel. 2: This variant is a deletion of a splice acceptor site. 3: Analyzed by TruSight ${ }^{\boxplus}$ Cardio Sequencing kit. 4: This patient also presented a $0.02 \mathrm{Mb}$ pathogenic deletion at 5q22.2. 5: Already described [23].

\section{Conclusions}

To the best of our knowledge, the present report would be the first study of the contribution of genetic causes in a cohort of patients with CA applying CMA and NGS approaches in Argentina. Using a rational algorithm that combines molecular techniques with clinical and genetic evaluation, we were able to determine the genetic cause in $26.2 \%$ of the patients with MCA or iCHD analyzed until now. Karyotype anomalies were found in $13.4 \%$ of MCA patients, whereas imbalances in the 22q11 region were found in $20.5 \%$ of patients. The diagnostic yield of CMA, as a second or third-tier test for a cohort of MCA patients from the Argentinian public health system was 19\%. Importantly, microarray testing has been proven to be especially useful in the identification of clinically relevant CNVs among MCA patients from our cohort, all of whom would have otherwise remained undiagnosed. Finally, based on a phenotype-first approach, $67 \%$ of the patients analyzed by NGS presented a clinically relevant genetic variant related to the disease. One of the most promising results from our work was the novel nucleotide variants and CNVs described for the first time worldwide, contributing to a better understanding of phenotypic manifestation of the diseases. Further studies are in progress to analyze the remaining patients with CA from our cohort. 
Institutional Review Board Statement: All procedures performed in this study were in accordance with institutional and/or national research committee ethical standards and with the 1964 Helsinki declaration and its later amendments or comparable ethical standards. The study was approved by the ethics committee of the Administración Nacional de Laboratorios e Institutos de Salud (ANLIS), Buenos Aires, Argentina (Acta \# 14, 16 September 2013).

Informed Consent Statement: Informed consent was obtained from all subjects involved in the study.

Data Availability Statement: The data presented in this study are available on request from the corresponding author.

Acknowledgments: To the families who agreed to participate in this study and to the PID ACM-CC Group: Noemí Buzzalino, Tania Castro, Belén Benavídez Mori, Laura Antonietti, Natalia Arrospide, Emilia Scadizzo, Bioq. Verónica Qualina, Ezequiel Romero, Pilar Anoni, Fabián Tomasoni, Graciela Luna, María Luján Zalazar, Delfina Stremiz, Melvin Barrantes, Fernando Monti, Yamila Flores, Graciela Carballido, Viviana Heevel, Valeria Gómez, Natalia Molina, Cecilia Iraira, Claudia Cuesta, Valeria Vera, María Ángeles Vilardo, Leoncio Billordo, Jaquelin Garello, Víctor Marques, María Márquez, Mirta Raggio, Olga Mangiante, Daniela Amor, Mónica Jewtuszyk, Blanca Senra, Natalia Izzo, Mariana Brautigam, Felicitas Fumiere, Graciela Fernández, María del Carmen Arbones y Norma Cecotti.

\section{References}

1. Centers for Disease Control and Prevention (CDC). Update on Overall Prevalence of Major Birth Defects-Atlanta, Georgia, 1978-2005. MMWR Morb. Mortal. Wkly. Rep. 2008, 57, 1-5. Available online: https://www.ncbi.nlm.nih.gov/pubmed/18185492 (accessed on 19 February 2021).

2. Szczałuba, K.; Demkow, U. Array comparative genomic hybridization and genomic sequencing in the diagnostics of the causes of congenital anomalies. J. Appl. Genet. 2017, 58, 185-198, doi:10.1007/s13353-016-0376-z.

3. Winter, R.M.; Baraitser, M. Multiple Congenital Anomalies: A Diagnostic Compendium. Springer: Berlin/Heidelberg, Germany, 2013. Available: https://play.google.com/store/books/details?id=2XP1BwAAQBAJ (accessed on 19 February 2021).

4. Groisman, B.; Bidondo, M.P.; Barbero, P.; Gili, J.A.; Liascovich, R. RENAC: Registro Nacional de Anomalías Congénitas de Argentina. Archivos Argentinos de Pediatría. 2013, 111, 484-494. Available online: https://www.researchgate.net/ profile/Juan_Gili/publication/262762073_RENAC_Registro_Nacional_de_Anomalias_Congenitas_de_Argentina/links/53da661 b0cf2631430c8235b.pdf (accessed on 19 February 2021).

5. Agopian, A.J.; Evans, J.A.; Lupo, P.J. Analytic Methods for Evaluating Patterns of Multiple Congenital Anomalies in Birth Defect Registries. Birth Defects Res. 2018, 110, 5-11, doi:10.1002/bdr2.1115.

6. Michelson, D.J.; Clark, R.D. Optimizing Genetic Diagnosis of Neurodevelopmental Disorders in the Clinical Setting. Clin. Lab. Med. 2020, 40, 231-256, doi:10.1016/j.cll.2020.05.001.

7. Zeitlin, J.; Mohangoo, A.; Cuttini, M.; EUROPERISTAT Report Writing Committee; Alexander, S.; Barros, H.; Blondel, B.; Bouvier-Colle, M.H.; Buitendijk, S.; Cans, C.; et al. The European Perinatal Health Report: Comparing the health and care of pregnant women and newborn babies in Europe. J. Epidemiol. Community Health 2009, 63, 681-682, doi:10.1136/jech.2009.087296.

8. Lu, X.-Y.; Phung, M.T.; Shaw, C.A.; Pham, K.; Neil, S.E.; Patel, A.; Sahoo, T.; Bacino, C.A.; Stankiewicz, P.; Kang, S.-H.L.; et al. Genomic imbalances in neonates with birth defects: High detection rates by using chromosomal microarray analysis. Pediatrics 2008, 122, 1310-1318, doi:10.1542/peds.2008-0297.

9. Miller, D.T.; Adam, M.P.; Aradhya, S.; Biesecker, L.G.; Brothman, A.R.; Carter, N.P.; Church, D.M.; Crolla, J.A.; Eichler, E.E.; Epstein, C.J.; et al. Consensus statement: Chromosomal microarray is a first-tier clinical diagnostic test for individuals with developmental disabilities or congenital anomalies. Am. J. Hum. Genet. 2010, 86, 749-764, doi:10.1016/j.ajhg.2010.04.006.

10. Pierpont, M.E.; Brueckner, M.; Chung, W.K.; Garg, V.; Lacro, R.V.; McGuire, A.L.; Mital, S.; Priest, J.R.; Pu, W.T.; Roberts, A.; et al. Genetic Basis for Congenital Heart Disease: Revisited: A Scientific Statement from the American Heart Association. Circulation 2018, 138, e653-e711, doi:10.1161/CIR.0000000000000606.

11. DeLea, M.; Espeche, L.D.; Bruque, C.D.; Bidondo, M.P.; Massara, L.S.; Oliveri, J.; Brun, P.; Cosentino, V.R.; Martinoli, C.; Tolaba, N.; et al. Genetic Imbalances in Argentinean Patients with Congenital Conotruncal Heart Defects. Genes 2018, 9, 454, doi:10.3390/genes9090454.

12. Vianna, G.S.; Medeiros, P.F.V.; Alves, A.F.; Silva, T.O.; Jehee, F.S. Array-CGH analysis in patients with intellectual disability and/or congenital malformations in Brazil. Genet. Mol. Res. 2016, 15, doi:10.4238/gmr.15017769.

13. Lay-Son G, Espinoza K, Vial C, Rivera JC, Guzmán ML, Repetto GM. Chromosomal microarrays testing in children with developmental disabilities and congenital anomalies. J Pediatr. 2015, 91, 189-195, doi:10.1016/j.jped.2014.07.003.

14. Zanardo, E.A.; Dutra, R.L.; Piazzon, F.B.; Dias, A.T.; Novo-Filho, G.M.; Nascimento, A.M.; Montenegro, M.M.; Damasceno, J.G.; Madia, F.A.R.; Da Costa, T.V.M.M.; et al. Cytogenomic assessment of the diagnosis of 93 patients with developmental delay and multiple congenital abnormalities: The Brazilian experience. Clinics 2017, 72, 526-537, doi:10.6061/clinics/2017(09)02. 
15. McGowan-Jordan, J.; Simons, A.; Schmid, M. ISCN 2016: An International System for Human Cytogenomic Nomenclature (2016). Karger 2016, doi:10.1159/isbn.978-3-318-06861-0.

16. Espeche, L.D.; Solari, A.P.; Mori, M. Ángeles; Arenas, R.M.; Palomares-Bralo, M.; Pérez, M.; Martínez, C.; Lotersztein, V.; Segovia, M.; Armando, R.; et al. Implementation of chromosomal microarrays in a cohort of patients with intellectual disability at the Argentinean public health system. Mol. Biol. Rep. 2020, doi:10.1007/s11033-020-05743-6.

17. Massara, L.S.; DeLea, M.; Espeche, L.; Bruque, C.D.; Oliveri, J.; Brun, P.; Furforo, L.; Dain, L.; Rozental, S. Double Autosomal/Gonosomal Mosaic Trisomy 47,XXX/47,XX,+14 in a Newborn with Multiple Congenital Anomalies. Cytogenet Genome Res. 2019, 159, 137-142, doi:10.1159/000504238.

18. Richards, S.; Aziz, N.; Bale, S.; Bick, D.; Das, S.; Gastier-Foster, J.; Grody, W.W.; Hegde, M.; Lyon, E.; Spector, E.; et al. Standards and guidelines for the interpretation of sequence variants: A joint consensus recommendation of the American College of Medical Genetics and Genomics and the Association for Molecular Pathology. Genet. Med. 2015, 17, 405-424, doi:10.1038/gim.2015.30.

19. Santos, M.V.P.F.; Gamba, B.F.; Empke, S.L.L.; de Oliveira Alves, C.C.; Bérgamo, N.A.; Ribeiro-Bicudo, L.A. Congenital Heart Disease Revealing Familial 22q11 Deletion Syndrome. Int. J. Cardiovasc. Sci. 2020, 33, 425-426, doi:10.36660/ijcs.20180060.

20. Jiang, L.; Hou, Z.; Duan, C.; Chen, B.; Chen, Z.; Li, Y.; Huan, Y.; Wu, K.K. Isolated congenital heart disease is associated with the 22q11 deletion even though it is rare. Int. J. Cardiol. 2010, 284-285, doi:10.1016/j.ijcard.2009.10.013.

21. Riggs, E.R.; Andersen, E.F.; Cherry, A.M.; Kantarci, S.; Kearney, H.; Patel, A.; Raca, G.; Ritter, D.I.; South, S.T.; Thorland, E.C.; et al. Technical standards for the interpretation and reporting of constitutional copy-number variants: A joint consensus recommendation of the American College of Medical Genetics and Genomics (ACMG) and the Clinical Genome Resource (ClinGen). Genet. Med. 2020, 245-257, doi:10.1038/s41436-019-0686-8.

22. Szczałuba, K.; Nowakowska, B.; Sobecka, K.; Smyk, M.; Castaneda, J.; Klapecki, J.; Kutkowska-Kaźmierczak, A.; Śmigiel, R.; Bocian, E.; Radkowski, M.; et al. Application of Array Comparative Genomic Hybridization in Newborns with Multiple Congenital Anomalies. Adv. Exp. Med. Biol. 2016, 912, 1-9, doi:10.1007/5584_2016_235.

23. Mendez, R.; Delea, M.; Dain, L.; Rittler, M. A novel pathogenic frameshift variant of KAT6B identified by clinical exome sequencing in a newborn with the Say-Barber-Biesecker-Young-Simpson syndrome. Clin. Dysmorphol. 2020, 29, 42, doi:10.1097/MCD.0000000000000270. 